\title{
Cross-linking and $\boldsymbol{O}$-Acetylation of Newly Synthesized Peptidoglycan in Staphylococcus aureus $\mathbf{H}$
}

\author{
By MICHAEL A. SNOWDEN,${ }^{1}+$ HAROLD R. PERKINS, ${ }^{1}{ }^{*}$ \\ ANNE W. WYKE, ${ }^{2}$ MICHAEL V. HAYES ${ }^{2}$ AND J. BARRIE WARD ${ }^{2}$ \\ ${ }^{1}$ Department of Genetics and Microbiology, University of Liverpool, Life Sciences Building, \\ PO Box 147, Liverpool L69 3BX, UK \\ ${ }^{2}$ Glaxo Group Research Ltd, Greenford, Middlesex UB6 OHE, UK
}

(Received 14 June 1989; revised 31 July 1989; accepted 4 August 1989)

\begin{abstract}
Staphylococcus aureus $\mathrm{H}$ growing exponentially was labelled with $\mathrm{N}$-acetyl[ $\left.{ }^{14} \mathrm{C}\right]$ glucosamine, which became incorporated into the peptidoglycan. The portion of peptidoglycan not linked to teichoic acid (60-75\% of the whole) was degraded with Chalaropsis muramidase to yield disaccharide-peptide monomers and dimers, trimers and oligomers formed by biosynthetic cross-linking of the monomers. The degree of $O$-acetylation of these fragments was also examined. Pulse-chase experiments showed that the proportion of label initially in the monomer fraction immediately after the $1 \mathrm{~min}$ pulse declined rapidly during a $3 \mathrm{~min}$ chase, while the oligomer fraction (fragments greater than trimer) gained the radioactivity proportionately. The radioactivity of the dimer and trimer fractions remained virtually unchanged. At 4 min after the commencement of labelling (i.e. approx. one-tenth of a generation time) final values had been reached. The $O$-acetylation of all fragments had achieved final values even at $1 \mathrm{~min}$, except for the monomer fraction, which showed an increase from $40 \%$ to $60 \%$ during the first $3 \mathrm{~min}$ of chase. Although $O$-acetylation was clearly a very rapid process, no $O$-acetylated peptidoglycan lipid-intermediates could be detected.
\end{abstract}

\section{INTRODUCTION}

The peptidoglycan of staphylococci has long been known to be highly cross-linked (Mandelstam \& Strominger, 1961) and to have $O$-acetyl groups on about $60 \%$ of its $\mathrm{N}$ acetylmuramic acid residues (Ghuysen \& Strominger, 1963). The early stages of cross-linking and post-synthetic modification of the peptidoglycan of Escherichia coli (de Pedro \& Schwarz, 1981; Burman \& Park, 1984), Proteus mirabilis (Gmeiner \& Kroll, 1981; Gmeiner \& Sarnow, 1987 ) and Neisseria gonorrhoeae (Lear \& Perkins, 1983, 1986; Dougherty, 1983a, $b$ ) have been examined by somewhat comparable studies of initial uptake and incorporation of labelled components, while since the pioneering studies of Tipper \& Strominger (1968), work on Staphylococcus aureus has been aimed more at wall turnover than at initial incorporation (Blümel et al., 1979). The relationship between the degree of $O$-acetylation and growth conditions has also been examined by Johannsen et al. (1983). The present experiments were designed to discover the processes by which peptidoglycan newly synthesized by growing Staph. aureus became incorporated into the cross-linked network of the wall, and how rapidly the new muramic acid units became $O$-acetylated. To achieve these aims, growing bacteria were pulselabelled with radioactive $N$-acetylglucosamine and the label was then 'chased' either by harvesting the cells and resuspending them in unlabelled medium or more simply by direct addition of excess unlabelled precursor. At various times during the chase period the cell walls were isolated as TCA-insoluble material, which was then solubilized by digestion with

† Present address: Glaxo Group Research Ltd, Greenford, Middlesex UB6 0HE, U.K. 
Chalaropsis muramidase B. Teichoic acids (also labelled because they contain $N$-acetylglucosamine residues) and the units of peptidoglycan covalently attached to them were removed by ion-exchange chromatography. The remaining fragments of peptidoglycan consisted of $\mathrm{N}$ acetylglucosaminyl- $\beta(1 \rightarrow 4)-N$-acetylmuramic acid disaccharide units (with or without $O$ acetylation of the $C_{6}$ position on the muramic acid) attached either to a single branched peptide chain (monomer) or cross-linked via D-alanyl-glycyl peptide bonds (Mandelstam \& Strominger, 1961) to another similar unit (dimer), to two such units (trimer) or to more of them (oligomers). These fragments were separated by TLC.

\section{METHODS}

Organism and growth conditions. Staphylococcus aureus $\mathrm{H}$ (NCIB 6571) was grown in nutrient broth (Oxoid no. 2, $\left.50 \mathrm{~g}^{-1}\right)$ at $37^{\circ} \mathrm{C}$ with rotatory shaking at 180 r.p.m. from a $1 \%(\mathrm{v} / \mathrm{v})$ inoculum of a $16 \mathrm{~h}$ culture. Growth was followed by measuring $O D_{585}$; during the exponential phase, mean generation time was 30-35 min.

Pulse-chase labelling of peptidoglycan. Mid-exponential-phase cultures $\left(40 \mathrm{ml}, \mathrm{OD}_{585} 0.6\right)$ were labelled with $N$ acetyl-D- $\left[1{ }^{-14} \mathrm{C}\right] g l u c o s a m i n e ~\left(2.15 ~ M B q \mu \mathrm{mol}^{-1} ; 55.5 \mathrm{kBq} \mathrm{ml}^{-1}\right.$; Amersham) for $1 \mathrm{~min}$. Then one of the following procedures was applied. Either (i) cells were collected by filtration ( $0.45 \mu \mathrm{m}$ Millipore, type $\mathrm{HA})$ and immediately resuspended $(2-3 \mathrm{~min})$ in an equal volume of prewarmed 'conditioned medium' containing $5 \mathrm{mM}-\mathrm{N}$ acetylglucosamine. ('Conditioned medium' consisted of a similar filtrate from a parallel, but unlabelled, culture. Under these conditions the resuspended cells grew immediately and exponentially. Samples of TCA-precipitate tested for radioactivity showed that the chase procedure was effective in preventing further incorporation and also that there was no significant loss of radiolabel during the $30 \mathrm{~min}$ chase period.) $\mathrm{Or}$ (ii) $\mathrm{N}$-acetylglucosamine was added directly to the culture to a final concentration of $100 \mathrm{mM}$.

At intervals after the pulse labelling, samples $(5 \mathrm{ml})$ were removed and added to an equal volume of $10 \%(\mathrm{w} / \mathrm{v})$ TCA at $4{ }^{\circ} \mathrm{C}$. The progress of incorporation was measured by filtering samples $(100 \mu \mathrm{l})$ on to glass microfibre filters $(\mathrm{GF} / \mathrm{C}$, Whatman). After washing once with ice-cold $1 \%(\mathrm{v} / \mathrm{v})$ acetic acid $(10 \mathrm{ml})$ and three times with water $(10$ $\mathrm{ml}$ ) the filters were dried and their radioactivity measured by scintillation counting. The remainder of the sample $(9.9 \mathrm{ml})$ was similarly filtered and washed and prepared for digestion with muramidase.

Muramidase digestion. TCA-precipitates on glass filters prepared as described above were dried overnight at room temperature and each placed in a flat-bottomed vial (i.d. $25 \mathrm{~mm}$ ). Chalaropsis muramidase B (EC 3.2.1.17; Hash \& Rothlauf, 1967) ( $30 \mathrm{mM}$-triethylamine acetate buffer pH 4.7, $500 \mu \mathrm{l}$; enzyme $50 \mu \mathrm{g} \mathrm{ml}^{-1}$ ) was added to cover the filter and incubated at $37^{\circ} \mathrm{C}$ for $16 \mathrm{~h}$. The digest and water washes $(3 \times 1 \mathrm{ml})$ were centrifuged to remove debris $(11600 \mathrm{~g}, 3 \mathrm{~min})$ and concentrated by rotary evaporation. The digest contained $95 \%$ of the label originally located in the TCA-precipitate.

Removal of teichoic acid and covalently linked peptidoglycan. These components were removed by adsorption on to a prepacked quaternary ammonium ion-exchange column (SAX, Analytichem International) essentially as described by Wyke et al. $(1981)$. The column $(0.5 \times 1 \mathrm{~cm})$ was washed with methanol $(1 \mathrm{ml})$ and equilibrated with deionized distilled water. Samples $(1-3 \mathrm{ml})$ were drawn through the column into a $5 \mathrm{ml}$ syringe and washings of $2 \times 1 \mathrm{ml}$ water were added before concentration by rotary evaporation. The peptidoglycan fragments not retained by the column contained $60-75 \%$ of the original label incorporated.

Chromatography $(T L C)$ and measurement of radioactivity of peptidoglycan fragments. The procedures, based on those of Tipper \& Strominger (1968) and Martin \& Gmeiner (1979) were exactly as described by Lear \& Perkins (1986).

Separation of peptidoglycan fragments into monomers, dimers, etc., by HPLC. The fragments obtained after digestion with Chalaropsis muramidase (equivalent to $200-400 \mu \mathrm{g}$ peptidoglycan) were applied to a gel filtration column (TSK SW2000, $600 \times 7.5 \mathrm{~mm}$ ) with a guard column (TSK SW2000G, $75 \times 7.5 \mathrm{~mm}$ ). The samples were eluted with $50 \mathrm{mM}$-sodium phosphate buffer ( $\mathrm{pH} 7.0$ ) at $0.3 \mathrm{ml} \mathrm{min}^{-1}$, by using a Waters model 510 pump. Peaks were detected at $214 \mathrm{~nm}$ with a Waters model 441 detector. Radioactivity was measured by scintillation counting of $5 \mu 1$ samples from $0.5 \mathrm{~min}$ fractions.

Amidase digestion of peptidoglycan fragments. In some experiments the product of muramidase digestion, after removal of teichoic acids and linked components, was digested with $\mathrm{N}$-acetylmuramoyl-L-alanine amidase (EC 3.5.1.28) from Streptomyces albus G, prepared by a modification of the method of Ghuysen et al. (1969). Digested peptidoglycan fragments were suspended to a final concentration of $4 \mathrm{mg} \mathrm{ml}^{-1}$ in $40 \mu \mathrm{l}$ of the amidase preparation ( $1 \mathrm{mg}$ protein $\mathrm{ml}^{-1}$ ) contained in $0.2 \mathrm{M}$-sodium acetate buffer $\mathrm{pH} 5.6$.

The suspension was incubated at $37^{\circ} \mathrm{C}$ for $16 \mathrm{~h}$, dried under vacuum, resuspended in $10 \mu \mathrm{l}$ water and analysed by TLC (Fig. 1).

Amino acid analysis. The PICO-TAG Amino Acid Analysis System (Waters UK) was used. Samples containing $10-100 \mu \mathrm{mol}$ of amino acid were hydrolysed in sealed evacuation vials in $6 \mathrm{M}-\mathrm{HCl}\left(105^{\circ} \mathrm{C}, 18 \mathrm{~h}\right)$. The hydrolysates 


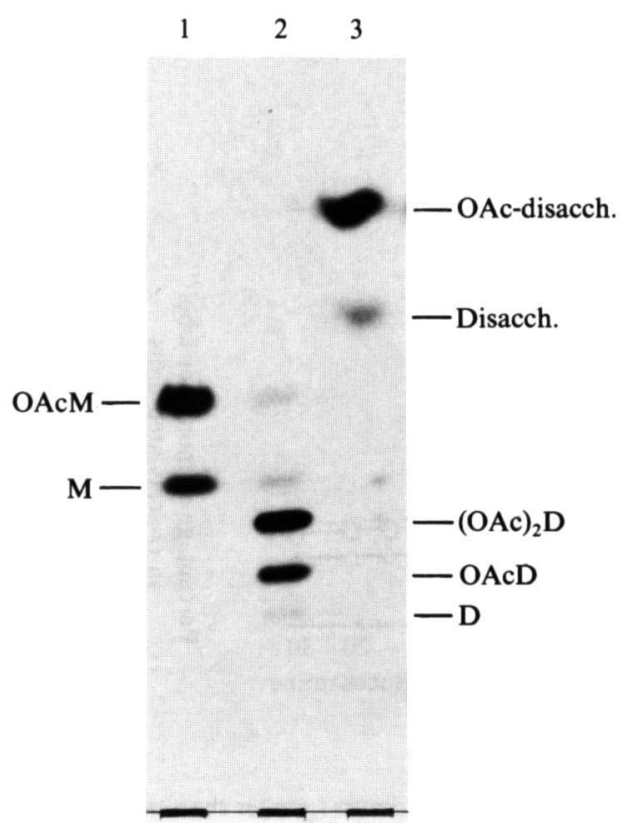

Fig. 1. Separation of peptidoglycan fragments by TLC. Peptidoglycan labelled with $N$-acetyl[ $\left.{ }^{14} \mathrm{C}\right]$ glucosamine was degraded with Chalaropsis muramidase, and monomer and dimer fragments were separated by HPLC. Monomers (lane 1) and dimers (lane 2) were applied directly to the TLC. Disaccharides (lane 3) were formed by treatment of peptidoglycan oligomers with amidase from Streptomyces albus $\mathrm{G}$ (for details see text). For system of abbreviations, see Table 1 ( $M$, monomer; disacch., disaccharide).

were dried and derivatized with phenylisothiocyanate as recommended by the manufacturers. The phenylthiocarbamyl amino acid derivatives were separated by HPLC C18 reverse-phase chromatography (Heinrikson \& Meredith, 1984). Peaks were detected at $254 \mathrm{~nm}$ and integrated by using an Apple Ile computer with software from U-Sci Ltd.

\section{RESULTS}

Cross-linking of newly synthesized peptidoglycan

When Staph. aureus $\mathbf{H}$ growing exponentially was pulse-labelled for only 1 min with $\mathrm{N}$ acetyl $\left[{ }^{14} \mathrm{C}\right]$ glucosamine, the incorporated hexosamine present as both glucosamine and muramic acid in the peptidoglycan was found in extensively cross-linked as well as in uncrosslinked (monomer) fragments even at the earliest times (Fig. 2). Thus immediately after the pulse the proportions of total label in dimer and trimer fractions had already reached values that would remain virtually constant for the whole of the chase period (one generation time). The mean values \pm SD $(n=16)$ over the period were: dimers $18.3 \pm 0.87 \%$, and trimers $18.4 \pm 1.29 \%$. The greatest observable changes were in the monomer fraction, which contained $54 \%$ of the incorporated label $1 \mathrm{~min}$ after addition of radioactivity (i.e. immediately at the end of the pulse), the proportion decreasing linearly with the exponent of time to $16 \cdot 3 \%$ during the next $3 \mathrm{~min}$, and then remaining almost constant; concomitantly, the proportion of label in the oligomer fraction (i.e. all oligomers greater than trimer) began at $13.2 \%$, increased linearly with the exponent of time to $44.7 \%$ during the next $3 \mathrm{~min}$, and thereafter underwent little change. The oligomer fraction is complex, containing oligomers in a size range up to at least icosamers (unpublished results). It was not possible to measure changes within subclasses of the oligomer fraction in the present experiments, but it would be reasonable to assume that such changes occur. 


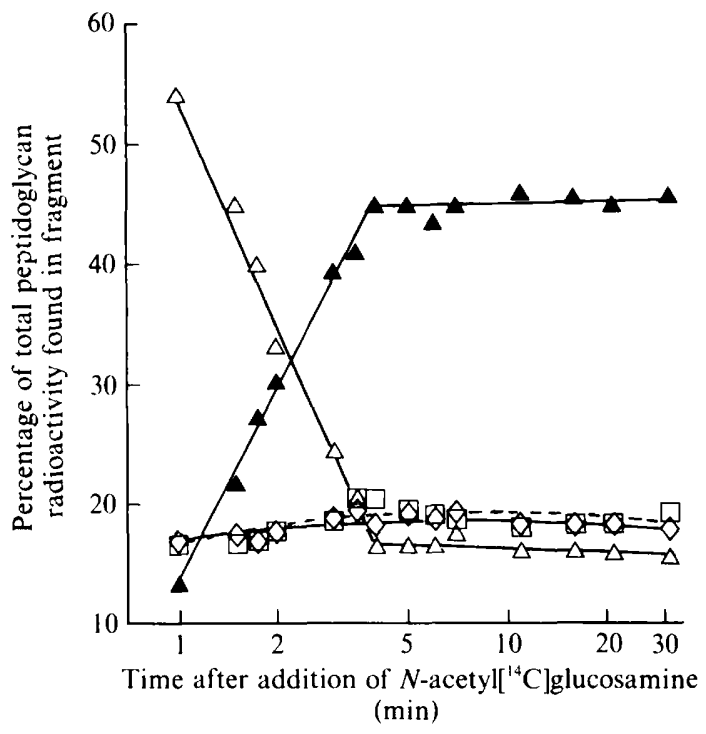

Fig. 2

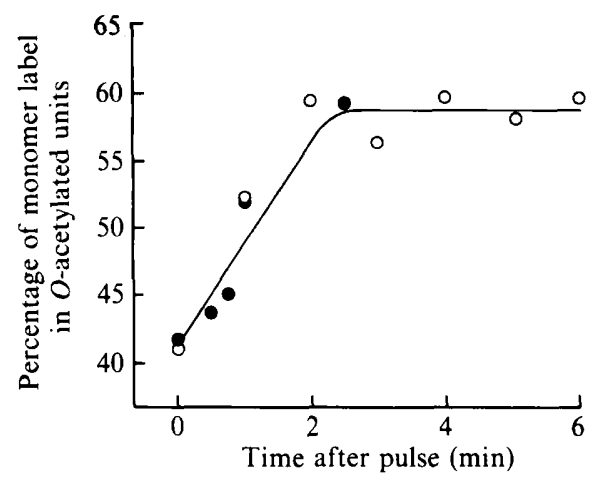

Fig. 3

Fig. 2. Proportion of monomers and oligomers (greater than trimer) in peptidoglycan labelled with $N$ acetyl[ $\left.{ }^{14} \mathrm{C}\right]$ glucosamine for $1 \mathrm{~min}$ prior to a chase period in unlabelled medium. The peptidoglycan was digested with Chalaropsis muramidase and the teichoic-acid-free portion separated into monomers, dimers, trimers and higher oligomers by HPLC (for details see Methods). $\triangle$, Monomers; $\diamond$, dimers; $\square---\square$, trimers; $\Delta$, oligomers.

Fig. 3. $O$-Acetylation of monomers during a pulse-chase experiment. The experimental procedure is described in Table 1 and in the text. $O$, Expt $1 ; 0$, expt 2.

\section{O-Acetylation of newly synthesized peptidoglycan}

When the distribution of $O$-acetylation among the various classes of newly labelled peptidoglycan fragments was examined by the procedures described in Methods it became apparent that there was no appreciable lag in the $O$-acetylation of cross-linked units. The values recorded at the end of the $1 \mathrm{~min}$ pulse (i.e. immediately after addition of $5 \% \mathrm{TCA}$ at $4{ }^{\circ} \mathrm{C}$ ) were the same as those found at any subsequent time (Table 1). Further, the class of dimer or trimer in which the new peptidoglycan found itself, whether it were non-, mono-, or a higher order of $O$-acetylated fragment, also did not change during the chase period. To check if the labelling of $O$-acetylated and non- $O$-acetylated units of cross-linked dimers and trimers was indeed uniform, as has been assumed for calculations of the degree of $O$-acetylation of these fractions (Table 1 ), samples for time points up to $6 \mathrm{~min}$ were further digested with amidase to yield the corresponding free disaccharides, which were separated by TLC and their radioactivity measured. The degrees of $O$-acetylation for dimers and trimers calculated from these results agreed, within experimental error, with those calculated on the assumption of uniform labelling.

The only portion of the total peptidoglycan in which a change in $O$-acetylation could be detected after a 1 min pulse was the uncross-linked (monomer) fraction (Fig. 3). Here the degree of $O$-acetylation was just above $40 \%$ immediately after the pulse and rose to its terminal value of nearly $60 \%$ within about 2-3 min. Comparison with Fig. 2 shows that it was at approximately the same point in the chase period that the initial surfeit of label in monomer disappeared, whereafter the proportions in monomer, dimer, trimer and oligomers remained essentially constant.

The results in Table 1 and Fig. 3 also show that at any time beyond the first 3 min of chase the degree of $\mathrm{O}$-acetylation deduced from the distribution of newly incorporated hexosamines had reached a uniform value of about $60 \%$, regardless of the degree of cross-linking. This result 
Table 1. O-Acetylation of cross-linked peptidoglycan fragments during the chase period after pulse-labelling

Staph. aureus $\mathrm{H}$ growing exponentially was labelled for $1 \mathrm{~min}$ with $\mathrm{N}$-acetyl[ $\left.{ }^{14} \mathrm{C}\right]$ glucosamine. In each experiment the total amount of label incorporated into TCA-insoluble wall material was $2.55 \mathrm{MBq}$ per $5 \mathrm{ml}$ of culture. Chase up to $6 \mathrm{~min}$ (expt 1) or $2.5 \mathrm{~min}$ (expt 2) after the pulse was procured by immediate addition of unlabelled precursor to a final concentration of $100 \mathrm{mM}$. After TCA precipitation and muramidase digestion, samples were analysed by HPLC followed by TLC. For details see Methods. The degree of $O$-acetylation of the cross-linked fragments (as opposed to the uncross-linked monomers; see Fig. 3) did not change appreciably with time. In expt 1 samples were taken at $0,1,2,3,4,5$ and $6 \mathrm{~min}$; in expt 2 at $0,0.5,0.75$ and $2.5 \mathrm{~min}$. The values indicate the distribution of $O$-acetyl groups within sub-classes of dimers and trimers and for the unresolved oligomers. Abbreviations: $\mathrm{D}$, dimer; $(\mathrm{OAc})_{2} \mathrm{D}$, di- $O$-acetylated dimer; $\mathrm{OAcD}$, mono- $O$-acetylated dimer; $\mathrm{T}$, trimer; $(\mathrm{OAc})_{3} \mathrm{~T}$, tri- $O$ acetylated trimer, etc.

\begin{tabular}{|c|c|c|c|c|c|c|c|c|c|c|}
\hline & \multicolumn{3}{|c|}{$\begin{array}{l}\text { Percentage of label in } \\
\text { dimer fraction found as: }\end{array}$} & \multirow{2}{*}{$\begin{array}{c}\text { Percentage } \\
\text { of dimer } \\
O \text {-acetylated* }\end{array}$} & \multicolumn{4}{|c|}{$\begin{array}{l}\text { Percentage of label in trimer } \\
\text { fraction found as: }\end{array}$} & \multirow{2}{*}{$\begin{array}{c}\text { Percentage } \\
\text { of trimer } \\
O \text {-acetylated }\end{array}$} & \multirow{2}{*}{$\begin{array}{l}\text { Percentage } \\
\text { of oligomer } \\
O \text {-acetylated }\end{array}$} \\
\hline & $(\mathrm{OAc})_{2} \mathrm{D}$ & $\mathrm{OAcD}$ & D & & $(\mathrm{OAc})_{3} \mathrm{~T}$ & $(\mathrm{OAc})_{2} \mathrm{~T}$ & OAcT & $\mathrm{T}$ & & \\
\hline \multicolumn{11}{|c|}{ Expt $1(n=7)$} \\
\hline Mean & $38 \cdot 2$ & $41 \cdot 6$ & $20 \cdot 1$ & $59 \cdot 1$ & $27 \cdot 4$ & $36 \cdot 1$ & $24 \cdot 9$ & $11 \cdot 6$ & 59.8 & 57.9 \\
\hline SD & 1.59 & $2 \cdot 84$ & 1.66 & 0.80 & 0.97 & 0.93 & 1.59 & 1.54 & 0.86 & 1.90 \\
\hline \multicolumn{11}{|c|}{ Expt $2(n=4)$} \\
\hline Mean & $38 \cdot 4$ & $40 \cdot 5$ & $20 \cdot 6$ & 58.6 & $25 \cdot 7$ & $35 \cdot 8$ & $27 \cdot 2$ & $11 \cdot 3$ & 58.6 & $59 \cdot 0$ \\
\hline SD & $2 \cdot 78$ & 2.96 & $2 \cdot 15$ & 1.48 & 1.51 & 0.65 & 0.55 & 1.46 & 1.55 & 1.42 \\
\hline
\end{tabular}

* Calculated as the percentage of total monomer units within the fraction that were $O$-acetylated, assuming that the label was equally distributed between $O$-acetylated and non- $O$-acetylated residues.

$\dagger$ Represents the percentage of the total radioactivity recovered as $O$-acetylated monomer after the oligomers had been converted to non-peptidated disaccharides (see Methods).

implies a close coupling of biosynthesis and control between the introduction of new units of peptidoglycan (i.e. disaccharides each attached to a stem peptide and pentaglycyl substituent) and the $O$-acetylation of a proportion of their muramyl residues.

\section{Are lipid-linked peptidoglycan precursors $O$-acetylated?}

The rapid appearance of labelled hexosamine in $O$-acetylated units $(40 \%$ in monomers and about $60 \%$ in cross-linked fractions immediately at the end of a $1 \mathrm{~min}$ pulse) raised the possibility that some $O$-acetylation of muramyl residues might occur even while the peptidoglycan precursors were lipid $\left(\mathrm{C}_{55}\right.$-undecaprenol)-linked (Higashi et al., 1967).

Lipid-intermediates from exponential cultures of Staph. aureus $\mathrm{H}$ labelled with $\mathrm{N}$ acetyl $\left[{ }^{14} \mathrm{C}\right]$ glucosamine were isolated by the method of Anderson et al. (1967) (for details see Lear \& Perkins, 1986). The material was then treated with $0.1 \mathrm{M}-\mathrm{HCl}$ at $100{ }^{\circ} \mathrm{C}$ for $1 \mathrm{~min}$, a procedure that hydrolyses the bond between the disaccharide and the lipid (Siewert \& Strominger, 1968) but does not remove $O$-acetyl groups from muramic acid residues (Lear $\&$ Perkins, 1986). A portion of the released disaccharide-peptide fragment was analysed for amino acids by HPLC (glutamic acid, lysine, alanine, glycine $1: 0 \cdot 87: 3 \cdot 1: 4 \cdot 3$ ). The remainder was divided into two, one half being directly examined by TLC and the other being first hydrolysed with amidase (see Methods). Autoradiography (Fig. 4) showed no sign of any $O$-acetylated precursor having been present, whereas the disaccharide-decapeptide (lane 1) and the free disaccharide liberated by amidase treatment (lane 4) were clearly identified. The slower-running material also present (lanes 1 and 4) was unidentified. It could theoretically have been $\mathrm{N}$ acetylmuramylpentapeptide derived from the monosaccharide lipid-intermediate. However, this seemed unlikely since $(a)$ it was unaffected by amidase treatment (lane 4$)$, and $(b)$ glycine is not normally added until the disaccharide-lipid-intermediate stage (Matsuhashi et al., 1967) and the overall amino acid analysis showed no deficiency of glycine. Possibly the slow-running component was derived by loss of lipid from a hexosamine-containing lipid-linked teichoic acid precursor (cf. Ward, 1981; Yokoyama et al., 1989). 


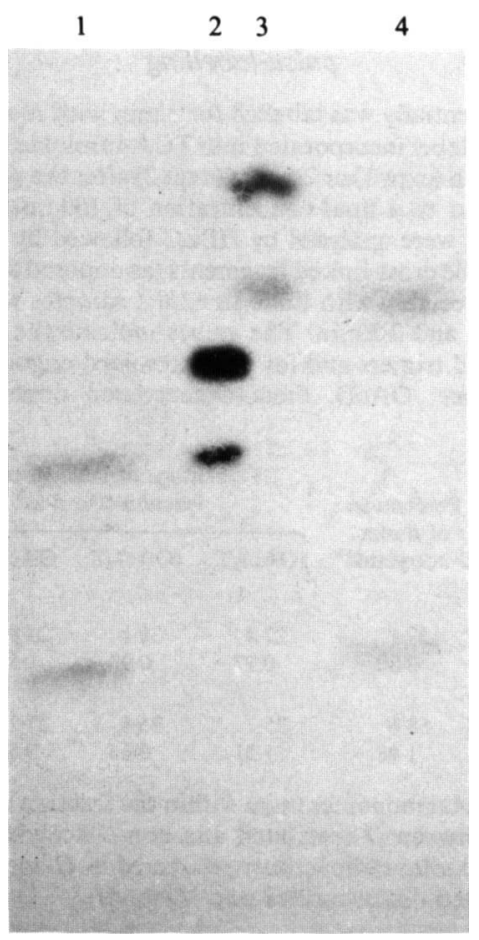

Fig. 4. Analysis by TLC of brief acid hydrolysates of lipid-intermediates isolated from Staph. aureus $\mathrm{H}$ labelled with $\mathrm{N}$-acetyl[ $\left.{ }^{14} \mathrm{C}\right]$ glucosamine. Chromatographically pure lipid-intermediate fraction was hydrolysed in $0 \cdot 1 \mathrm{M}-\mathrm{HCl}\left(100^{\circ} \mathrm{C}, 1 \mathrm{~min}\right)$ and the water-soluble product applied to TLC (lane 1). Another sample was first freed from its decapeptide substituent by treatment with amidase (lane 4). Markers: disaccharide, with and without $O$-acetyl group (see Fig. 1), lane 3; monomer, with and without $O$-acetyl group (see Fig. 1), lane 2.

\section{DISCUSSION}

It is important to emphasize that our work, and the whole of this discussion, relates to that portion of the peptidoglycan (the large majority) which was unlinked to teichoic acid. Since the early work of Tipper \& Strominger (1968) there has been little attempt to follow the progress of cross-linking in the peptidoglycan of Staph. aureus, and the pattern of development of the wellknown $O$-acetylation has not been examined. While some of the results of Tipper \& Strominger (1968) for Staph. aureus Copenhagen match our findings, e.g. the early diminution of the proportion of monomers and the eventual rise of the oligomers, the differences of strain, experimental design, label and separation methods are such that further direct comparison is unwarranted.

Peptidoglycan maturation processes involving secondary cross-linking have also been observed in Streptococcus faecalis (Dezélée \& Shockman, 1975) and E. coli (de Pedro \& Schwarz, 1981 ) and with the further involvement of continued $O$-acetylation in $P$. mirabilis (Gmeiner \& Kroll, 1981) and $N$. gonorrhoeae (Lear \& Perkins, 1983, 1986). In all cases the contrast with Staph. aureus is marked. In the only other Gram-positive organism, Strep. faecalis, Dezélée \& Shockman (1975) observed that during the chase period after a $1 \mathrm{~min}$ pulse of an exponential culture the proportion of peptidoglycan monomer decreased from $23 \%$ to $11 \%$ over $8 \mathrm{~min}$ and continued to decline slowly thereafter, while the corresponding values for oligomers greater than trimer were $17 \%$ and $29 \%$ with a further small rise. However, unlike in Staph. aureus, there was a smaller but distinct decrease in the dimer fraction (35\% to $31 \%)$ and a corresponding increase in the trimer fraction $(24 \%$ to $30 \%)$. Two clear differences from Staph. aureus $\mathrm{H}$ emerge : first, that 
in Strep. faecalis dimers and trimers represent a far bigger proportion of the total peptidoglycan and are subject to inverse changes in proportions during maturation; and second, that the whole process of maturation in Strep. faecalis is much slower, although the mean generation time is about the same ( $35 \mathrm{~min})$.

In the Gram-negative bacteria the initial degree of cross-linking [ $30 \%$ in $N$. gonorrhoeae (Lear \& Perkins, 1983, 1986); 20\% in E. coli (de Pedro \& Schwarz, 1981); $21 \%$ in P. mirabilis (recalculated from the results of Gmeiner \& Kroll, 1981)] underwent a relatively slow period of maturation up to about one generation time, during which cross-linking increased to $35 \%, 30 \%$ and $28 \%$ respectively. In the species that have $O$-acetylated peptidoglycan the degrees of $O$-acetylation also rose slowly from low initial values until they reached their final state, again after about one generation time. Once more the rapidity of cross-linking in Staph. aureus peptidoglycan stands out, while the fact that the $O$-acetylation of its cross-linked component is fully achieved at the earliest observable times (Table 1) and that even the monomer becomes fully $O$-acetylated within $3 \mathrm{~min}$ (Fig. 3), again makes this species exceptional among those that have so far been investigated.

Although we could detect no sign of $O$-acetylation of muramyl residues at or before the lipidintermediate stage of peptidoglycan biosynthesis (as indeed was also observed in $N$. gonorrhoeae: Lear \& Perkins, 1986), the results suggest that $O$-acetylation must be very closely linked with the addition of peptidoglycan units to the growing polymer. At present it is not possible to say for certain whether the $O$-acetylation occurs concomitantly with the crosslinking, or fractionally precedes it. The fact that the cross-linked components appear at all times to be at their final degree of $O$-acetylation could indicate that there is preferential cross-linking of regions of peptidoglycan already $O$-acetylated to the final extent, thus accounting for the relative depletion at early times in $O$-acetylation of the as yet uncross-linked monomer units. This model would also account for the fact that we could detect no asymmetry in $O$-acetylation of the newly synthesized dimers and trimers, since the probability of a labelled unit being $O$ acetylated would be determined before cross-linking occurred. The same lack of asymmetry may well have been true for the oligomers but our experimental procedures did not allow us to answer that question.

The fact that dimers and trimers remain at essentially constant proportions during the early chase period while monomer declines and oligomer increases presumably indicates that gains of newly synthesized monomer units to the dimers and trimers are almost exactly compensated for by losses, from the latter to higher oligomers. The observed proportions of label in monomers : dimers : trimers : oligomers $(1: 1 \cdot 24: 1 \cdot 31: 3 \cdot 3)$ may be compared with the overall values for proportions of total disaccharide-peptide units found by chemical methods in exponentially growing cells $(1: 1 \cdot 29: 1 \cdot 33: 8 \cdot 1$; unpublished results). The agreement for the dimers and trimers is very close but there is a clear deficiency of label in the oligomer fraction. Thus the amount of label found in larger oligomers would underestimate the proportion of those oligomers present. If a monomer addition model as proposed for Strep. faecalis by Oldmixon et al. (1976) were to operate in its simplest form then one would predict that the labelling of all oligomers would be essentially in proportion to the amount of those oligomers present, which was clearly not the case. The implication, therefore, is that the monomer addition model may be inappropriate for Staph. aureus.

M. A. Snowden wishes to thank the SERC for a CASE Studentship.

\section{REFERENCES}

Anderson, J. S., Matsuhashi, M., Haskin, M. A. \& Strominger, J. L. (1967). Biosynthesis of the peptidoglycan of bacterial cell wall. II. Phospholipid carriers in the reaction sequence. Journal of Biological Chemistry 242, 3180-3190.

BlÜMel, P., UeCKer, W. \& Giesbrecht, P. (1979). Zero order kinetics of cell wall turnover in Staphylococcus aureus. Archives of Microbiology 121, 103-110.
Burman, L. G. \& Park, J. T. (1984). Molecular model for elongation of the murein sacculus of Escherichia coli. Proceedings of the National Academy of Sciences of the United States of America 81, 1844-1848.

Dezélée, P. \& Shockman, G. D. (1975). Studies of the formation of peptide cross-links in the cell wall peptidoglycan of Streptococcus faecalis. Journal of Biological Chemistry 250, 6806-6816. 
DOUGHERTY, T. J. (1983a). Synthesis and modification of the peptidoglycan in Neisseria gonorrhoeae. FEMS Microbiology Letters 17, 51-53.

Dougherty, T. J. (1983b). Peptidoglycan synthesis in Neisseria gonorrhoeae strains sensitive and intrinsically resistant to $\beta$-lactam antibiotics. Journal of Bacteriology 153, 429-435.

Ghuysen, J.-M. \& STROMINGER, J. L. (1963). Structure of the cell wall of Staphylococcus aureus strain Copenhagen II. Separation and structure of disaccharides. Biochemistry 2, 1119-1125.

GhuYsen, J.-M., DieRickX, L., CoYetTe, J., LeYHBouille, M., Guinand, M. \& Campbell, J. N. (1969). An improved technique for the preparation of Streptomyces peptidases and $N$-acetylmuramyl-Lalanine amidase active on bacterial wall peptidoglycans. Biochemistry 8, 213-219.

Gmeiner, J. \& Kroll, H.-P. (1981). Murein biosynthesis and $O$-acetylation of $N$-acetylmuramic acid during the cell division cycle of Proteus mirabilis. European Journal of Biochemistry 117, 171-177.

GmeINER, J. \& SARNOW, E. (1987). Murein biosynthesis in synchronized cells of Proteus mirabilis. Quantitative analysis of $O$-acetylated murein sub-units and of chain termina ins incorporated into the sacculus during the cell cycie. European Journal of Biochemistry 163, 389-395.

Hash, J. H. \& Rothlauf, M. V. (1967). The $N, O$ diacetylmuramidase of Chalaropsis species. Purification and crystallization. Journal of Biological Chemistry 242, 5586-5590.

Heinrikson, R. L. \& Meredith, S. C. (1984). Amino acid analysis by reverse phase high-performance liquid chromatography: precolumn derivatisation with phenylisothiocyanate. Analytical Biochemistry 136, 65-67.

Higashi, Y., Strominger, J. L. \& Sweeley, C. C. (1967). Structure of a lipid intermediate in cell wall biosynthesis; a derivative of $\mathrm{C}_{55}$-isoprenoid alcohol. Proceedings of the National Academy of Sciences of the United States of America 57, 1878-1884.

JohanNSEN, L., LABISCHINSKI, H., Reinecke, B. \& GiesBrecht, P. (1983). Changes in the chemical structure of walls of Staphylococcus aureus grown in the presence of chloramphenicol. FEMS Microbiology Letters 16, 313-316.

Lear, A. L. \& Perkins, H. R. (1983). Degrees of $O$ acetylation and cross-linking of the peptidoglycan of Neisseria gonorrhoeae during growth. Journal of General Microbiology 129, 885-888.

LEAR, A. L. \& Perkins, H. R. (1986). O-Acetylation of peptidoglycan in Neisseria gonorrhoeae. Investiga- tion of lipid-linked intermediates and glycan chains newly incorporated into the cell wall. Journal of General Microbiology 132, 2413-2420.

Mandelstam, M. H. \& Strominger, J. L. (1961). On the structure of the cell wall of Staphylococcus aureus (Copenhagen). Biochemical and Biophysical Research Communications 5, 466-471.

Martin, H. H. \& GMeIner, J. (1979). Modification of peptidoglycan structure by penicillin-action in cell walls of Proteus mirabilis. European Journal of Biochemistry 95, 487-495.

Matsuhashi, M., Dietrich, C. P. \& Strominger, J. L. (1967). Biosynthesis of the peptidoglycan of bacterial cell walls. III. The role of soluble ribonucleic acid and of lipid intermediates in glycine incorporation in Staphylococcus aureus. Journal of Biological Chemistry 242, 3191-3206.

OldmiXon, E. H., Dezélée, P., Ziskin, M. C. \& Shockman, G. D. (1976). Monomer addition as a mechanism of forming peptide cross-links in the cell wall peptidoglycan of Streptococcus faecalis ATCC 9790. European Journal of Biochemistry 68, 271-280.

De Pedro, M. A. \& Schwaizz, U. (1981). Heterogeneity of newly inserted and pre-existing murein in the sacculus of Escherichia coli. Proceedings of the National Academy of Sciences of the United States of America 78, 5856-5866.

Siewert, G. \& STROMinger, J. L. (1968). Biosynthesis of the peptidoglycan of bacterial cell walls. Formation of the isoglutamine amino group in the cell wall of Staphylococcus aureus. Journal of Biological Chemistry 243, 783-790.

TIPPER, D. J. \& STROMinger, J. L. (1968). Biosynthesis of the peptidoglycan of bacterial cell walls. XII. Inhibition of cross-linking by penicillins and cephalosporins: studies in Staphylococcus aureus in vivo. Journal of Biological Chemistry 243, 3169-3179.

WARD, J. B. (1981). Teichoic and teichuronic acids: biosynthesis, assembly and location. Microbiological Reviews 45, 211-243.

WYKe, A. W., WARD, J. B., HAYES, M. V. \& CuRtis, N. A. C. (1981). A role in vivo for penicillin binding protein 4 of Staphylococcus aureus. European Journal of Biochemistry 119, 389-393.

Yoxoyama, K., Mizuguchi, H., ARaki, Y., Kaya, S. \& ITO, E. (1989). Biosynthesis of linkage units for teichoic acids in Gram-positive bacteria: distribution of related enzymes and their specificities for UDP-sugars and lipid-linked intermediates. Journal of Bacteriology 171, 940-946. 